\title{
Inhibitory effects of minocycline on gliosis in the hydrocephalic
} H-Tx rat

\author{
Janet M Miller*1,2,3, Alexander G Shanku1 ${ }^{1}$, Steven D Ham ${ }^{3}$ and \\ James P McAllister II 1,2,3
}

\begin{abstract}
Address: ${ }^{1}$ Department of Neurosurgery, Wayne State University, 550 East Canfield 048 Lande MRB, Detroit, MI 48201, USA, ${ }^{2}$ Department of Physiology, Wayne State University, 550 East Canfield 048 Lande MRB, Detroit, MI 48201, USA and ${ }^{3}$ Department of Pediatric Neurosurgery, Wayne State University, 550 East Canfield 048 Lande MRB, Detroit, MI 48201, USA

Email: Janet M Miller* - jmiller@med.wayne.edu

* Corresponding author
\end{abstract}

from 50th Annual Meeting of the Society for Research into Hydrocephalus and Spina Bifida

Cambridge, UK. 30 August -2 September 2006

Published: 21 December 2006

Cerebrospinal Fluid Research 2006, 3(SuppI I):SI7 doi:I0.II86/1743-8454-3-SI-SI7

(C) 2006 Miller et al; licensee BioMed Central Ltd.

\section{Background}

Persistent gliosis, if present in the hydrocephalic brain, has the potential to alter the biomechanical properties of the brain, impair cerebral perfusion, impede neuronal regeneration and affect plasticity. The purpose of this study was to determine the ability of minocycline, a specific inhibitor of glial reactivity, to reduce glial scar formation in the H-Tx rat model of congenital hydrocephalus.

\section{Materials and methods}

Minocycline (45 mg/kg/day i.p. in 5\% sucrose) was administered to 6 hydrocephalic and 5 non-hydrocephalic animals, from postnatal days 15 through 21 . These treated animals were compared to age-matched 21 day untreated control and hydrocephalic littermates $(\mathrm{n}=$ 5 each). Cortical tissue was paraffin embedded and selected regions subjected to immunohistochemistry using Ionized calcium binding adaptor molecule 1(IBA1) to label microglia and Glial Fibrillary Acidic Protein (GFAP) to label astrocytes. Tissue sections were then analyzed using light microscopy and non-biased stereology to quantify the density of these specific glial cells.

\section{Results}

Minocycline was effective in reducing the relative amount of both microglia and astrocytes present in the treated hydrocephalic animals compared to untreated animals.
Hydrocephalic animals receiving minocycline exhibited a significant $(\mathrm{p}<0.05)$ reduction in astrocyte density by 2.93 fold and a significant $(\mathrm{p}<0.05)$ reduction of microglial density of 3.41 fold. Although minocycline treatment reduced the overall concentration of these glial cells compared to the untreated hydrocephalic animals, the treated hydrocephalic animals still possessed a significantly higher ( $\mathrm{p}<0.05)$ density of astrocytes (1.76 fold) and microglia ( 1.51 fold) than the untreated control animals. Minocycline also increased cortical thickness in the treated hydrocephalic group. The anterior portion of the occipital cortex in the treated hydrocephalic animals possessed a significantly $(\mathrm{p}<0.05)$ thicker cortex compared to the untreated hydrocephalic animals when measured at the dorsal (1.97 fold), lateral (2.10 fold) and temporal ( 2.88 fold) regions of the cerebral hemisphere.

\section{Conclusion}

Overall, our data suggest that relatively short-term minocycline treatment is effective in reducing the astrogliosis and microgliosis that accompanies ventriculomegaly while also increasing cortical thickness. The administration of this drug may therefore provide an added benefit when used as a supplement to ventricular shunting for the long-term control of gliosis. 